\begin{tabular}{|c|c|}
\hline 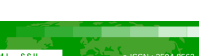 & Malaysian Journal of Social Sciences and Humanities (MJSSH) \\
\hline Malaysian Jounal of & Volume 4, Issue 7, November 2019 \\
\hline $\begin{array}{l}\text { Humanities } \\
\text { (MJ-sSH) }\end{array}$ & e-ISSN : 2504-8562 \\
\hline & $\begin{array}{l}\text { Journal home page: } \\
\text { www.msocialsciences.com }\end{array}$ \\
\hline
\end{tabular}

\title{
Pattern and Utilization of Maternal Health Services in Jigawa State, Nigeria
}

\author{
Muhammad Abdulkadir'1, Ruslan Rainis' ${ }^{1}$, Alshammari Eissa Zaidan², Murtala Uba Muhammad³, \\ Yamuna A. Kani4 \\ ${ }^{1}$ Geography Section, School of Humanities, Universiti Sains Malaysia (USM) \\ ${ }^{2}$ Geography Department, University of Ha'il, Saudi Arabia \\ ${ }^{3}$ Geography Department, Bayero University, Nigeria \\ ${ }^{4}$ Federal University, Dutse, Jigawa State, Nigeria
}

Correspondence: Muhammad Abdulkhadir (muhammad.abdulkadir@student.usm.my)

\begin{abstract}
One of the important goals of launching the Millennium Development Goals (MDGs) is maternal health. Nigeria was not able to achieved the target of reduction the maternal mortality as set by MDGs as a target. Nigeria has 37 state and Jigawa state is one of those state. The state has poor indices of health indicator, the maternal mortality is high and also antenatal visit in the state is not encouraging. The objective of the study was to find out the degree (extent) of the usage of the services of the maternal health care and to examine the role of socio-demographic variables and antenatal visit on the uses of the services of maternal health system available in the state. Logistic regression (Binary), chisquare, and bivariate analysis were used and the study used the data collected from the state ministry of health. The study utilized the data for two year (2017-2018). The finding of this study revealed that socio-economic factors greatly influence the uses of maternal health care services. Level of education (Women's education) influences the maternal health care utilization. The study found that, the hospital based delivery, antenatal care visit utilization and seeking service after delivery varies among the women with the different level of education, age at marriage, women's age and residence of women. The study revealed that, the women's with the high level of education (literate) is 2 times compared to illiterate women likely to use antenatal services $(\mathrm{OR}=1.97$, ANC1.95, full $\mathrm{ANC} p<0.01)$, also in terms of hospital delivery literate women is $(\mathrm{OR}=1.52, \mathrm{p}<0.01)$ or 1.53 times. Women's education encouragement and support should be advocated because is one among the many strategies to improve the utilisation of the services of maternal health.
\end{abstract}

Keywords: hospital based delivery, antenatal visit, Jigawa, socio-demographic, postnatal

\section{Introduction}

The issues of maternal health started receiving world attention after the Conference on Population and Development which was held Nairobi Kenya 1992 (ICPD), The high level of the ratio of the maternal death in less developed countries especially in sub Saharan Africa necessitated the International conference. The women condition while pregnancy is refers to as maternal health. The care of maternal health services includes the issues of antenatal visit (Routine medical check up by pregnant women), time of delivery and period after termination of pregnancy. 
Many women witnessed health problem at their age of reproductive more especially death during the pregnancy and delivery, this is more ordinary in less developed countries. Even though variation exist in the maternal death estimate amongst the nations, but still the estimates indicated that the maternal mortality is very high in sub Saharan Africa(Zahr, Wardlaw, \& Choi, 2004). Every day close to 800 pregnant women lost their life as a result of pregnancy or pregnancy complication, and this resulted to the 500 women yearly lost their lives(Ray, Bhandari, \& Prasad, 2018) Sadly, Countries in Africa registered the highest number of a women dyeing as a result of complication related to pregnancy, annually 253,000 women with the pregnancy related complication are dyeing (Organization, 2014). During the year 2010 Nigeria alone registered $10 \%$ of the world's total maternal mortality bearing in mind that Nigeria has only $2 \%$ of the world total population. The ratio of the death in the country (Nigeria) exceeds 1000 which is above average of African continent of 800 MMR. Less developed nation accounted for over 99 percent $(99 \%)$ of the total maternal mortality of the world(Zozulya, 2010).The maternal mortality varies within Nigeria; the serious concern is in the Northern Nigeria which experiencing experienced high maternal mortality (Adamu, 2014).

Improving and providing intervention and access to maternal services barrier removal will certainly help in reducing the maternal mortality. Many programme and policies were introduced by the federal republic of Nigeria in order to convert the maternal mortality; to our dismay the target of reducing maternal death by $50 \%$ as set by millennium development goal was not achieved(Fagbamigbe \& Idemudia, 2015; Gogoi, Unisa, \& Prusty, 2014) Modern services of maternal health care, utilisations and accessibility to those services greatly influence the outcome of health during after pregnancy(Singh, Rai, Alagarajan, \& Singh, 2012) Hospital based delivery. Antenatal and postnatal are three main components to be consider when measuring the rate of maternal services, even though is debatable on which factors to be considered. But many studies show and confirmed that these components greatly influence and considered as a predictor of the outcome of the reproductive (Panda \& Vashisht, 2014).

Socio economics and demographical factors have evidently shown by many studies that, these factors greatly influenced the utilisation and accessing the services of maternal health amongst pregnant women (Dixit, Dwivedi, \& Ram, 2013; Govindasamy \& Ramesh, 1997; Rai, Singh, \& Singh, 2012; Ray et al., 2018) National Family survey confirmed that the women's level of education largely determine the women's attitude in patronising the services of maternal health. Economic and social factors and religion are very important towards the maternal health services In Nigeria for example resident (rural or urban) and women's age is directly associated with the uses of maternal health and also deepen on the availability of those services in different state (NDH, 2018).

Nigeria is one of the countries in Africa with high maternal death and the health care system of the country is very ineffective. This is because of the budgetary allocation is very poor and even the minimum resources allocated, there is cases of misconduct, poverty is identified as the major barrier in accessing the maternal care service in the country.

The ratio of the maternal mortality in the country per 100,000 live births is 630 ; the ratio of the maternal mortality is also varies in the country with the geo political zone and within the state. The ratio is higher in the north western and north eastern part(Doctor et al., 2012). The maternal mortality of the country when compared to others in Africa is higher, for example it is 66 per 100,000 live births in Egypt and is 97 per 100,000 live births in Algeria. In Nigeria is one of the north western state in the country and has high maternal mortality, the state ratio of maternal mortality is per 100,000 live births 1000 (Health et al., 2005).

This study is tried to examine the role hospital based delivery, antenatal and postnatal and socio demographic variables influences the uses of services of maternal health. 


\section{Methods}

This study was conducted using the data collected from the ministry in charge of health in the Jigawa, Nigeria. The health office in the state has the central data based which they tagged it health management information system. The health office conducts yearly health survey which covered all the state. The survey is designed to give information in order to monitor the sector of health within the state. The survey is 4 of its kind to be conducted in the state. During the survey total number 28,778 married women between the ages of 15 to 49 years were interviewed. 8458 women were participated in this study.

\section{Variables}

This study takes into consideration basic three provided services at health institution for the pregnant women, hospital based delivery. Antenatal and postnatal services are the 3 basic services which many researchers considered as dependent variables. Complication from the Post delivery was also included in this study in order to get good result.

The study considered hospital based delivery. Antenatal and postnatal services are the dependent variables while the independent variables are religion, caste, women's age, Age at marriage, delivery type.

\section{Statistical analysis}

Inferential statistics were used to achieve the study objective; statistics techniques used are logistic regression (binary) chi square and bivariate analysis. In order to understand and explain the association of antenatal visit (full and any), delivery at hospital and seeking treatment from the complication after the termination of pregnancy with the various demographic and socio economic factors chi square was used. For the prediction of the ratios (odd ratio) and to know the significance of uses of the services of maternal health with women's socio demographic variables logistic regression analysis was employed. For the study to know and the inequality level of the utilization of the services among the women (wealth index) a confidence intervals were also used. All the analysis was conducted using the SPSS software.

\section{Results}

\section{Women Utilization Of Antenatal Services}

Table 1 shows the antenatal visit among the women base on the socio-demographic variables. The result revealed that women at age of 18 normally received ANC maximally (any ANC $70.7 \%$ and $16.2 \%$ full $\mathrm{ANC}$ ), old women whose are less than 18 are not utilizing the antenatal significantly difference of above 18 years mothers. $69.9 \%$ any ANC and full ANC $16.3 \%$ goes to women who are marrying later than a 18 years of age. Note that weighted analysis is used.

In terms of religion Muslim are to the rear (with $39 \%$ and $5.4 \%$ full ANC) when compared with Christians (ANC $=70 \%$, and $15.6 \%$ full ANC). The result also shows that the women's level of education also played an important role in accessing the antennal visit as women who are educated are seeking more or 2 time $17.2 \%$ full ANC. Rural women does not have access to ANC when compared to women living in urban areas. Women economic status also affects the antenatal visit. Middle and poor income status women attain less ANC than richer women.

\section{Logistic Regression Result (Difference In Receiving ANC)}

The logistic regression model (Bivariate logistic regression ) in Table 2 evidently shown that women level of education, economic status, residence (rural or urban)and religion are associated significantly 
with the Antenatal utilisation (any and Full ANC). Christians women are utilising almost ANC (both the ANC) at $56 \%(\mathrm{OR}$ is $0.441, \mathrm{P}=0,001)$ and (OR is $0.523, \mathrm{P}=0.01)$ as compared to Muslim. The research found that relationship exist positively between women's level of education and antenatal visit, educated women get two ANC at $(\mathrm{OR}-1.969, \mathrm{P}=0.001)$ for any $\mathrm{ANC}$ while for full ANC $(\mathrm{OR}=1.955, \mathrm{P}=0.01)$ than uneducated women. Note the reference category is denoted by $(\mathrm{R})$.

Table 1: Socio-demographic Variables of Women received ANC) in Jigawa, 2017-2018.

\begin{tabular}{lllll}
\hline Background & $\begin{array}{l}\text { Any } \\
\text { ANC }\end{array}$ & Full & N characteristics & ANC \\
\hline $\begin{array}{l}\text { Age of the women } \\
\text { Less than 18 }\end{array}$ & 60.5 & 8.3 & 626 \\
18 and above & 70.7 & 16.2 & 7832 \\
Age at first marriage & & & \\
Less than 18 & 62.5 & 10.8 & 2043 \\
18 and above & 69.9 & 16.3 & 6415 \\
Religion $^{\mathbf{a}}$ & & & \\
Muslim & 70 & 15.6 & 7826 \\
Christian & 39.9 & 5.4 & 561 \\
Caste & & & \\
SC/ST & 62 & 11.8 & 3043 \\
OBC & 67.8 & 15.5 & 2486 \\
Others & 75 & 17.8 & 2929 \\
Women education & & & \\
Illiterate & 48.4 & 6.7 & 1804 \\
Literate & 73.6 & 17.2 & 6654 \\
Residence & & & \\
Rural & 64.3 & 12.5 & 5139 \\
Urban & 75.3 & 19.6 & 3319 \\
Wealth index & & & \\
Poor & 57.9 & 9.7 & 3554 \\
Middle & 70.3 & 16.3 & 1704 \\
Rich & 78.8 & 20.3 & 3200 \\
Jigawa & 70.8 & 14.9 & 8458 \\
\hline & & & \\
\hline & & &
\end{tabular}

Table 2: Logistic Regression (Difference between any full ANC and ANC)

\begin{tabular}{|c|c|c|c|c|c|c|}
\hline $\begin{array}{l}\text { Socio-demographic } \\
\text { Variables }\end{array}$ & $\begin{array}{c}\text { Any ANC } \\
\text { Odds Ratio }\end{array}$ & $95 \% \mathrm{CI}$ & P value & $\begin{array}{l}\text { Full ANC } \\
\text { Odds Ratio }\end{array}$ & $95 \% \mathrm{CI}$ & $P$ value \\
\hline $\begin{array}{l}\text { Age of the women } \\
\text { Less than } 18(\mathrm{R})\end{array}$ & & & & & & \\
\hline $\begin{array}{l}18 \text { and above } \\
\text { Age at first marriage }\end{array}$ & 1.009 & $0.239-4.248$ & 0.990 & 1.016 & $0.124-8.324$ & 0.988 \\
\hline $\begin{array}{l}\text { Less than } 18(\mathrm{R}) \\
18 \text { and above }\end{array}$ & 1.078 & $0.963-1.206$ & 0.187 & $1.279 * * *$ & $1.090-1.501$ & 0.002 \\
\hline $\begin{array}{l}\text { Religion } \\
\text { Christian }\end{array}$ & & & & & & \\
\hline $\begin{array}{l}\text { Muslim } \\
\text { Others }\end{array}$ & $\begin{array}{l}0.441 * * * \\
0.998\end{array}$ & $\begin{array}{l}0.364-0.533 \\
0.753-1.322\end{array}$ & $\begin{array}{l}0.000 \\
0.989\end{array}$ & $\begin{array}{l}0.523 * * * \\
0.864\end{array}$ & $\begin{array}{l}0.359-0.752 \\
0.621-1.202\end{array}$ & $\begin{array}{l}0.001 \\
0.386\end{array}$ \\
\hline $\begin{array}{l}\text { Caste } \\
\text { SC/ST(R) }\end{array}$ & & & & & & \\
\hline $\mathrm{OBC}$ & $1.259 * * *$ & $1.117-1.430$ & 0.000 & $1.249 * * *$ & $1.065-1.464$ & 0.006 \\
\hline Others & $1.268^{* * *}$ & $1.119-1.437$ & 0.000 & 1.102 & $0.942-1.291$ & 0.223 \\
\hline
\end{tabular}




\begin{tabular}{lcccccc}
$\begin{array}{l}\text { Literate } \\
\text { Residence } \\
\text { Rural(R) }\end{array}$ & $1.969 * * *$ & $1.740-2.227$ & 0.000 & $1.955^{* * *}$ & $1.579-2.419$ & 0.000 \\
$\begin{array}{l}\text { Urban } \\
\text { Wealth Index }\end{array}$ & $1.358 * * *$ & $1.222-1.509$ & 0.000 & $1.439 * * *$ & $1.268-1.633$ & 0.000 \\
$\begin{array}{l}\text { Poor(R) } \\
\text { Middle }\end{array}$ & & & & & & \\
Rich & $1.252 * * *$ & $1.093-1.433$ & 0.001 & $1.394 * * *$ & $1.163-1.671$ & 0.000 \\
& $1.657 * * *$ & $1.453-1.890$ & 0.000 & $1.570 * * *$ & $1.331-1.853$ & 0.000 \\
\hline
\end{tabular}

\section{Delivery place chosen by women}

The percentage of women according to their delivery place (Government or Private) was depicted in Table 3. Government hospital is more preferred by the women of age of 18 years with $45 \%$ while private hospital is only $23 \%$. Many women also prefer to deliver at home with about $53.7 \%$. Majority of the women who follow religion of Islam prefer to deliver at home with $15 \%$. The most interesting thing is that less educated women prefer to deliver at government hospital with about $43.3 \%$.

Women with high economic status normally go to the private hospital to deliver while middle and low economic status women go to the hospital owned by the government to deliver. Place of residence also determine delivery place as women living in rural prefer government hospital than the private with about $36.1 \%$.

\section{Logistic regression analysis (difference in receiving Hospital delivery)}

Table 4 revealed that hospital based delivery greatly reduces if the age of marriages (age at first marriage) reduces. $34.7 \%$ who married at the age of 18 and above years (OR-1.35, $\mathrm{P}=0.01)$ prefer hospital based delivery. $57.6 \%$ of Muslim women $(\mathrm{OR}=0.423, \mathrm{P}=0.01)$ are prefer not hospital based delivery with the Christian women. It is very important to note that educated women who prefer hospital base delivery (government and private) are $52 \%$. The association positively exist between women economic status and delivery place. If the economic status of women increases the hospital based delivery increases also $(\mathrm{OR}=1.95)$.

Table 3: Distribution of women by Delivery place in Jigawa State, 2017-2018

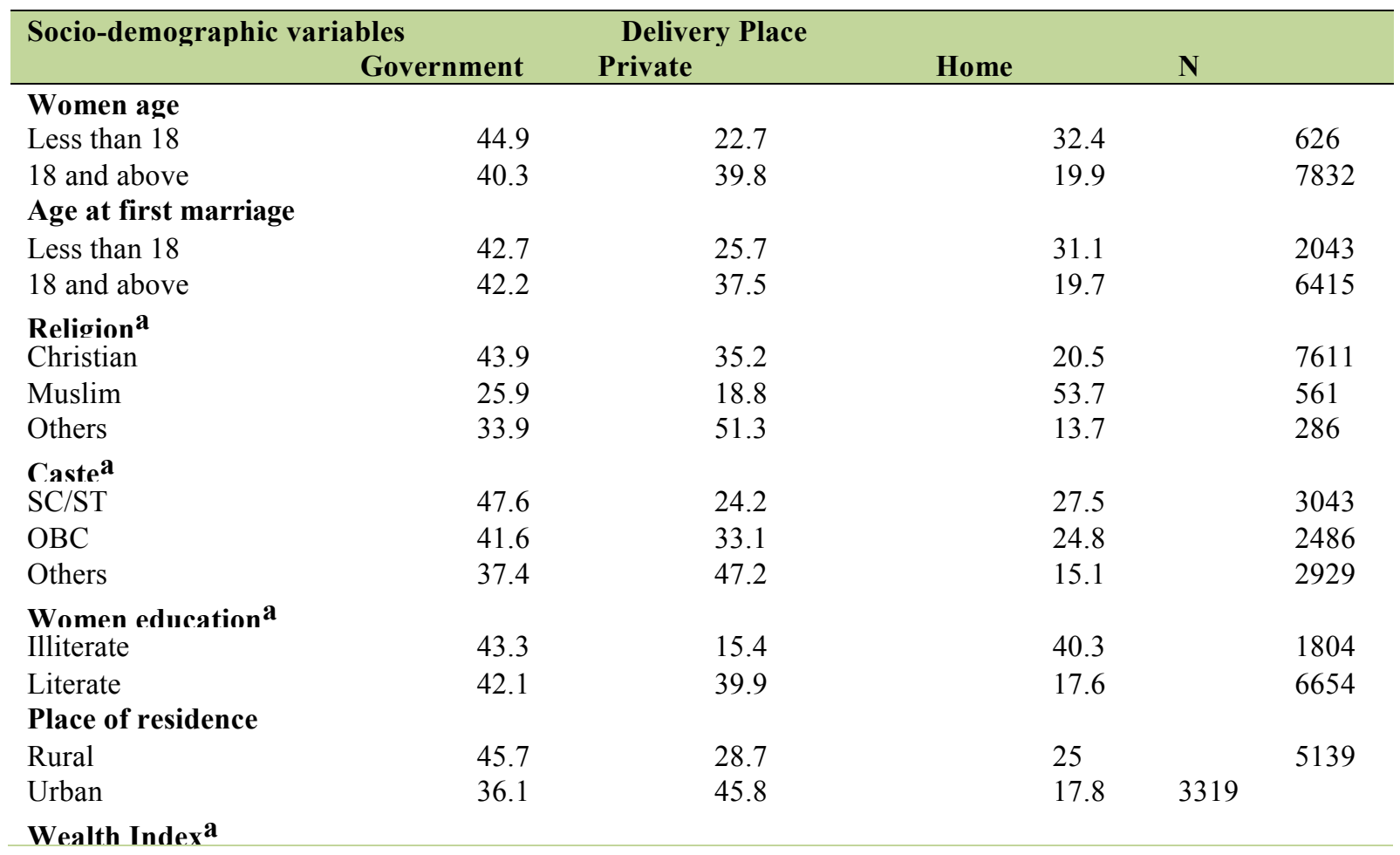




\begin{tabular}{lllll} 
Poor & 47.9 & 19 & 33.2 & 3554 \\
Middle & 44.8 & 34 & 21.6 & 1704 \\
Rich & 34.7 & 53.6 & 11.5 & 3200 \\
Anv ANC & & & & \\
No & 37.3 & 18.5 & 43.1 & 2568 \\
Yes & 44.6 & 41.8 & 13.3 & 5890 \\
Full ANC & & & & \\
No & 41.7 & 33 & 24.7 & 7166 \\
Yes & 46.1 & 43.9 & 10.1 & 1292 \\
Jigawa & 42.4 & 34.6 & & 8458 \\
\hline
\end{tabular}

Table 4: Logistic regression of difference of women received Hospital bases delivery

\begin{tabular}{|c|c|c|c|}
\hline Socio-demographic Variables & Odds Ratio & 95\% Confidence Interval & P value \\
\hline \multicolumn{4}{|l|}{ Age of women } \\
\hline \multicolumn{4}{|l|}{ Less than $18(\mathrm{r})$} \\
\hline 18 and above & 0.915 & $0.171-4.875$ & 0.918 \\
\hline \multicolumn{4}{|l|}{ Age at First Marriage } \\
\hline \multicolumn{4}{|l|}{ Less than $18(\mathrm{r})$} \\
\hline 18 and above & $1.347 * * *$ & $1.188-1.528$ & 0.000 \\
\hline \multicolumn{4}{|l|}{ Religion } \\
\hline \multicolumn{4}{|l|}{ Christian(r(r) } \\
\hline Muslim & $0.424 * * *$ & $0.346-0.519$ & 0.000 \\
\hline Others & 1.082 & $0.760-1.540$ & 0.660 \\
\hline \multicolumn{4}{|l|}{ Caste } \\
\hline \multicolumn{4}{|l|}{$\mathrm{SC} / \mathrm{ST}(\mathrm{r})$} \\
\hline $\mathrm{OBC}$ & 1.092 & $0.952-1.251$ & 0.206 \\
\hline Others & $1.310 * * *$ & $1.130-1.519$ & 0.000 \\
\hline \multicolumn{4}{|l|}{ Women's level of education } \\
\hline \multicolumn{4}{|l|}{ Illiterate(r) } \\
\hline Literate & $1.520 * * *$ & $1.325-1.743$ & 0.000 \\
\hline \multicolumn{4}{|l|}{ Residence } \\
\hline \multicolumn{4}{|l|}{ Rural(r) } \\
\hline Urban & 1.037 & $0.917-1.172$ & 0.562 \\
\hline \multicolumn{4}{|l|}{ Wealth Index } \\
\hline \multicolumn{4}{|l|}{ Poor(r) } \\
\hline Middle & $1.215^{* *}$ & $1.041-1.418$ & 0.013 \\
\hline Rich & $1.946 * * *$ & $1.661-2.279$ & 0.000 \\
\hline \multicolumn{4}{|l|}{ Any ANC } \\
\hline \multicolumn{4}{|l|}{ No(r) } \\
\hline Yes & $3.612 * * *$ & $3.206-4.068$ & 0.000 \\
\hline \multicolumn{4}{|l|}{ Full ANC } \\
\hline No(r) & & & \\
\hline Yes & $1.316^{* * *}$ & $1.070-1.618$ & 0.009 \\
\hline
\end{tabular}

\section{Complication after delivery and seeking its treatment}

Complication arising after the termination of pregnancy was shown in Table 5. About $15 \%$ of women in Jigawa face complication after delivery and which among them only $55.3 \%$ seek medical or treatment from the hospital. Women among the religion of Islam suffered from complication after pregnancy $(16 \%)$ and the complication is $16.7 \%$ in $\mathrm{OBC}$ women group. (SC/ST $(15.2 \%)$,others (13.8\%). Women living in rural community suffered most from these complications with about $14.7 \%$, and only about $48 \%$ among the less educated women sought treatment. Poverty determines women intention to receive treatment as because of poverty only $52 \%$ were able to look for treatment. 


\section{Logistic Regression Analysis (Differences in seeking treatment of complication after delivery)}

Religion is associated significantly with the seeking treatment of complication after termination of pregnancy (Table 6). Women who attended one of the antenatal (any or Full ANC) are 1.98 times to go to the physicians seeking treatment $(\mathrm{OR}=198, \mathrm{P}=0.01)$ and $1.23(\mathrm{OR}=1.267, \mathrm{P}=0.01)$. Delivery type also has relation significantly with treatment.

Table 5: Distribution of women suffers from post-delivery complication in Jigawa, 2017-2018.

\begin{tabular}{|c|c|c|c|c|}
\hline Socio-demographic Variables & Complication after delivery & $\mathbf{N}$ & Sought treatment & $\mathbf{N}$ \\
\hline \multicolumn{5}{|l|}{ Age of women } \\
\hline Less than 18 & 17.3 & 626 & 49.4 & 108 \\
\hline 18 and above & 14.9 & 7832 & 56.3 & 1176 \\
\hline \multicolumn{5}{|l|}{ Age at first marriage } \\
\hline Less than 18 & 15.0 & 2043 & 52.3 & 306 \\
\hline 18 and above & 15.3 & 6415 & 56.3 & 978 \\
\hline \multicolumn{5}{|l|}{ Religion* } \\
\hline Christian & 15.0 & 7611 & 54.9 & 1137 \\
\hline Muslim & 15.5 & 561 & 54.0 & 91 \\
\hline Other & 20.1 & 286 & 65.9 & 56 \\
\hline \multicolumn{5}{|l|}{ Caste** } \\
\hline $\mathrm{SC} / \mathrm{ST}$ & 15.2 & 3043 & 54.2 & 459 \\
\hline OBC & 16.7 & 2486 & 56.1 & 419 \\
\hline Other & 13.8 & 2929 & 55.9 & 406 \\
\hline \multicolumn{5}{|l|}{ Women level of education $* * *$} \\
\hline Illiterate & 15.7 & 1804 & 47.5 & 285 \\
\hline Literate & 15.1 & 6654 & 57.6 & 999 \\
\hline \multicolumn{5}{|l|}{ Residence* } \\
\hline Rural & 14.7 & 5139 & 56.9 & 749 \\
\hline Urban & 16.2 & 3319 & 52.6 & 535 \\
\hline \multicolumn{5}{|l|}{ Wealth index* } \\
\hline Poor & 15.8 & 3554 & 51.9 & 562 \\
\hline Middle & 15.6 & 1704 & 55.5 & 248 \\
\hline Rich & 14.3 & 3200 & 58.8 & 458 \\
\hline \multicolumn{5}{|l|}{ Any ANC $^{* * * *}$} \\
\hline No & 11.1 & 2650 & 41.0 & 299 \\
\hline Yes & 17.1 & 5808 & 59.7 & 985 \\
\hline \multicolumn{5}{|l|}{ Full ANC $* * *$} \\
\hline No & 14.8 & 7166 & 53.3 & 1058 \\
\hline Yes & 17.4 & 1292 & 65.3 & 226 \\
\hline \multicolumn{5}{|l|}{ TT $* * *$} \\
\hline No & 11.7 & 2811 & 40.3 & 333 \\
\hline Yes & 17.0 & 5647 & 60.6 & 951 \\
\hline \multicolumn{5}{|l|}{ IFA*** } \\
\hline No & 14.1 & 6228 & 52.6 & 882 \\
\hline Yes & 18.2 & 2230 & 61.3 & 402 \\
\hline \multicolumn{5}{|l|}{ Delivery place $* * *$} \\
\hline Home & 12.6 & 1918 & 45.1 & 239 \\
\hline Government & 15.9 & 3545 & 53.5 & 566 \\
\hline Private & 16.0 & 2995 & 63.0 & 479 \\
\hline \multicolumn{5}{|l|}{ Delivery type ${ }^{* * *}$} \\
\hline Normal & 14.4 & 7506 & 52.2 & 239 \\
\hline other & 21.9 & 952 & 72.5 & 1045 \\
\hline Jigawa & 15.2 & 8458 & 55.3 & 1284 \\
\hline
\end{tabular}


Table 6: Logistic regression differences in treatment seeking for post-delivery complications

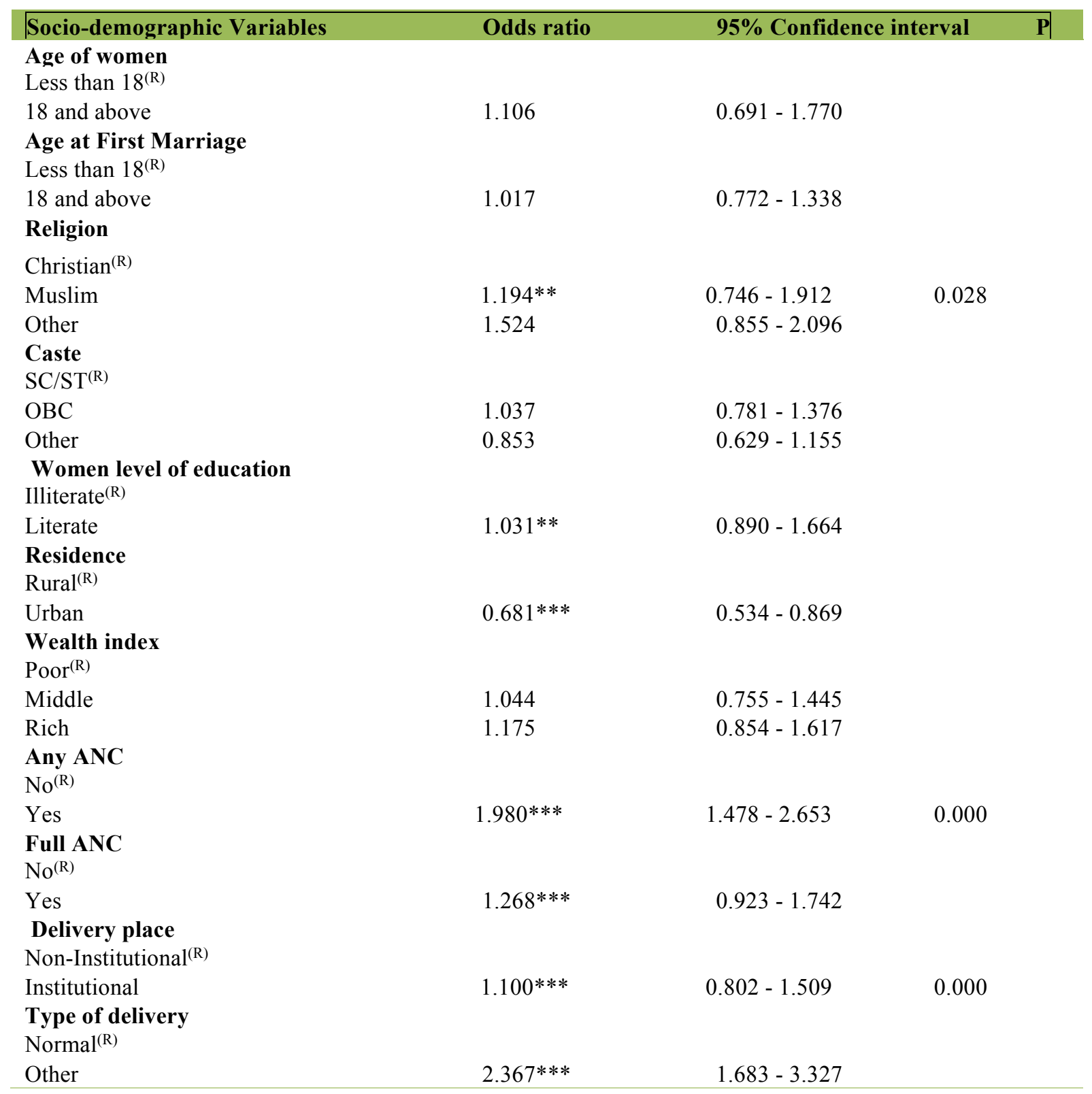

\section{Discussion}

The research finding indicated that there is difference in terms of antenatal visit in Jigawa state, the full antenatal when compared to ant antenatal is very low. Women who are 18 at their first marriage utilize and go for antenatal when compared with the women married at below the age of 18 . Sociodemographics variables (women's religion and caste) significantly play a vital role in seeking the services of maternal health. Any and full antenatal visit among women who followed religion of Islam is very low. In addition to that about $50 \%$ of the Muslim women wish to deliver at home than hospital delivery. They may go for treatment from complication after delivery. This is because most of the physicians are male and therefore many women think that is not allowed for them to go to the male doctors for treatment (Obiyan \& Kumar, 2015).

The research finding also revealed that educated women received and goes for antenatal when compared with the uneducated women. Any and Full ANC are two important variable (factors) which the affect the hospital base delivery (Idris, Gwarzo, \& Shehu, 2006; Simkhada, Teijlingen, Porter, \& Simkhada, 2008; Turan, Miller, Bukusi, Sande, \& Cohen, 2008). This study therefore is in line with the 
previous researches which confirmed that the powerful instruments in promoting the seeking behaviour of treatment and hospital delivery is antenatal visit(Dairo \& Owoyokun, 2010). Safe delivery is also measured and influence by the women level of education and economic status. Many research finding condemn the early marriage. This study corroborate with past finding which shows that the complication after delivery is low among women which their level of education is high and are expected to go for the treatment is higher when there is complication(Buor \& Bream, 2004; Nigussie, Mariam, \& Mitike, 2004; Rai et al., 2012) Therefore education plays an important role in ensuring safe delivery.

The study finding also believed that residence of women (Rural or Urban) also play significant and important role in the maternal health care utilization. The study indicated that urban areas is directly associated with possibility of utilizing the services of the maternal health. This is related to all the 3 indicators (Antenatal, hospital base delivery, and seeking after delivery). Many women as shown by the analysis that did not attend any maternal services for whatever reasons are at higher risk of suffering from the complication after delivery. Hospital delivery is associated negatively with complication after the termination of pregnancy and associated positively with complication after delivery (Islam, Chowdhury, \& Akhter, 2006; Mutihir \& Utoo, 2011; Mutiso, Qureshi, \& Kinuthia, 2008; Oladapo et al., 2016). Even though government introduce many programme is only about $15 \%$ of women who are living in rural Jigawa deliver at hospital. Mother at younger aged is vulnerable to complication after pregnancy (Naseem, Khattak, Ghazanfar, \& Irfan, 2017; Organization, 2017).

\section{Conclusion}

The level of education of women is indicated in this research that one possible ways that will improve and promote patronage of maternal services by women regardless of their economic status or location (Residence) and this will bring safe delivery and reduce the ratio of maternal death in less developed countries and Nigeria in particular. Women empowerment should also be given attention.

The antenatal visit usage will possibly increase and promote hospital based delivery and directly it will determine the seeking of treatment when there is a complication after delivery. It is therefore this study recommend that promotion ANC among the pregnant women. The study also recommends that to look into the health facilities distribution because majority health facilities were concentrated in the urban areas and this will reduce the gap between poor and high income class.

\section{Acknowledgment:}

The author wishes to acknowledge the effort of my supervisor and all the co-authors and Jigawa state ministry of health for releasing the data for this study.

\section{References}

Adamu, Y. M. (2014). Chapter Twenty Two. KANO, 347.

Buor, D., \& Bream, K. (2004). An analysis of the determinants of maternal mortality in sub-Saharan Africa. Journal of Women's Health, 13(8), 926-938.

Dairo, M., \& Owoyokun, K. (2010). Factors affecting the utilization of antenatal care services in Ibadan, Nigeria. Benin Journal of Postgraduate Medicine, 12(1).

Dixit, P., Dwivedi, L. K., \& Ram, F. (2013). Estimating the impact of antenatal care visits on institutional delivery in India: A propensity score matching analysis. Health, 5(05), 862.

Doctor, H. V., Findley, S. E., Ager, A., Cometto, G., Afenyadu, G. Y., Adamu, F., \& Green, C. (2012). Using community-based research to shape the design and delivery of maternal health services in Northern Nigeria. Reproductive health matters, 20(39), 104-112. 
Fagbamigbe, A. F., \& Idemudia, E. S. (2015). Assessment of quality of antenatal care services in Nigeria: evidence from a population-based survey. Reproductive health, 12(1), 88.

Gogoi, M., Unisa, S., \& Prusty, R. K. (2014). Utilization of maternal health care services and reproductive health complications in Assam, India. Journal of Public Health, 22(4), 351-359.

Govindasamy, P., \& Ramesh, B. (1997). Maternal education and the utilization of maternal and child health services in India.

Health, W. H. O. D. o. M., Abuse, S., Organization, W. H., health, W. h. o. D. o. m., health, s. a. M., evidence, ... Team, R. (2005). Mental health atlas 2005: World Health Organization.

Idris, S., Gwarzo, U., \& Shehu, A. (2006). Determinants of place of delivery among women in a semiurban settlement in Zaria, northern Nigeria. Annals of African medicine, 5(2), 68-72.

Islam, M. A., Chowdhury, R. I., \& Akhter, H. H. (2006). Complications during pregnancy, delivery, and postnatal stages and place of delivery in rural Bangladesh. Health Care for Women International, 27(9), 807-821.

Mutihir, J. T., \& Utoo, B. (2011). Postpartum maternal morbidity in Jos, north-central Nigeria. Nigerian journal of clinical practice, 14(1).

Mutiso, S., Qureshi, Z., \& Kinuthia, J. (2008). Birth preparedness among antenatal clients. East African medical journal, 85(6), 275-283.

Naseem, S., Khattak, U. K., Ghazanfar, H., \& Irfan, A. (2017). Maternal health status in terms of utilisation of antenatal, natal and postnatal services in a Periurban setting of Islamabad: A community based survey. J Pak Med Assoc, 67(8), 1186-1191.

Nigussie, M., Mariam, D. H., \& Mitike, G. (2004). Assessment of safe delivery service utilization among women of childbearing age in north Gondar Zone, North West Ethiopia. Ethiopian Journal of health development, 18(3), 145-152.

Obiyan, M. O., \& Kumar, A. (2015). Socioeconomic inequalities in the use of maternal health care services in Nigeria: trends between 1990 and 2008. Sage Open, 5(4), 2158244015614070.

Oladapo, O., Adetoro, O., Ekele, B., Chama, C., Etuk, S., Aboyeji, A., . . . Adegbola, O. (2016). When getting there is not enough: a nationwide cross-sectional study of 998 maternal deaths and 1451 near-misses in public tertiary hospitals in a low-income country. BJOG: An International Journal of Obstetrics \& Gynaecology, 123(6), 928-938.

Organization, W. H. (2014). Maternal mortality ratio (per 100,000 live births). Health Statistics and Information Systems. WHO, Geneva.

Organization, W. H. (2017). Progress in partnership: 2017 progress report on the Every woman every child global strategy for women's, children's and adolescents' health. Retrieved from

Panda, M., \& Vashisht, B. M. (2014). Practices related to delivery and antenatal care among females in rural block of Haryana, India. Muller Journal of Medical Sciences and Research, 5(1), 39.

Rai, R. K., Singh, P. K., \& Singh, L. (2012). Utilization of maternal health care services among married adolescent women: insights from the Nigeria Demographic and Health Survey, 2008. Women's Health Issues, 22(4), e407-e414.

Ray, S., Bhandari, P., \& Prasad, J. B. (2018). Utilization pattern and associated factors of maternal health care services in Haryana, India: a study based on district level household survey data. Int J Reprod Contracept Obstet Gynecol, 7, 1154-1163.

Simkhada, B., Teijlingen, E. R. v., Porter, M., \& Simkhada, P. (2008). Factors affecting the utilization of antenatal care in developing countries: systematic review of the literature. Journal of advanced nursing, 61(3), 244-260.

Singh, P. K., Rai, R. K., Alagarajan, M., \& Singh, L. (2012). Determinants of maternity care services utilization among married adolescents in rural India. PloS one, 7(2), e31666.

Turan, J. M., Miller, S., Bukusi, E., Sande, J., \& Cohen, C. (2008). HIV/AIDS and maternity care in Kenya: how fears of stigma and discrimination affect uptake and provision of labor and delivery services. AIDS care, 20(8), 938-945.

Zahr, C. A., Wardlaw, T. M., \& Choi, Y. (2004). Maternal mortality in 2000: estimates developed by WHO, UNICEF and UNFPA: World Health Organization.

Zozulya, M. (2010). Maternal mortality in Nigeria: An indicator of women's status. A Consultancy Africa Intelligence Publication. Source: http://www. consultancyafrica. com. Retrieved August. 